\title{
Compliance of Boiler Standards and Industrial Safety in Indian Subcontinent
}

\author{
Akshoy Ranjan Paul and Firoz Alam

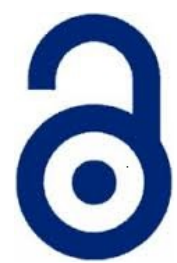 \\ Received: 15 August 2018 \\ Accepted: 29 September 2018 \\ Published: 01 December 2018 \\ Publisher: Deer Hill Publications \\ (c) 2018 The Author(s) \\ Creative Commons: CC BY 4.0
}

\begin{abstract}
The economic development and industrialisation necessitate the use of boilers/pressure vessels. With the increase of boiler numbers and uses, the boiler explosion is rising. The non-compliance of standards and regulations, poor operation, maintenance, repair and safety-awareness are considered to be the integral part of boiler accidents. Human error and poor maintenance are responsible for nearly $50 \%$ of the global boiler explosions. The fatalities due to boiler explosions are sky rocketing in the Indian subcontinent. The paper has reviewed the global boiler explosions fatalities with a special emphasis on boiler accidents occurred in the Indian subcontinent and suggested some remedial actions.
\end{abstract}

Keywords. Boiler, Pressure vessel, Industrial safety, Standards, Indian subcontinent

\section{INTRODUCTION}

The tragic stories associated with the boiler/pressure vessel explosions are made frequently the major headlines in print and electronic media. Nevertheless, many more such stories go unreported and overlooked. The boiler/pressure vessel explosions cause massive devastations regardless of their size or scope. The boiler explosions have significant consequences in developing nations as the explosions not only destroy property and human lives but also ruin livelihoods, and often the sole bread earners of poor families. A generation's dream is lost through the tragedies. Most tragedies could have been easily prevented if standards and guidelines were properly developed, understood, practised and enforced.

Boilers/pressure vessels are widely used in industries (power plants, chemical and fertilizer industries, paper mills, sugar mills, cotton mills, jute mills, rice mills, pharmaceuticals, textiles and garments industries) and homes and offices (water heating, central heating, cooking, and sanitation, etc.). Usually, a pressure vessel with the steam pressure ranging from 0.07 to $2 \mathrm{MPa}$ is called boiler, and above $2 \mathrm{MPa}$ is called steam generator. As per Australian Standard AS2593:2004 (Reconfirmed 2016) a boiler is defined as "An Arrangement of vessels and interconnecting parts, wherein steam or other vapour is generated, or water or other liquid is heated at a pressure above that of the atmosphere by the application of fire or the products of combustion or process, or by electrical or solar means. It also includes valves, gauges, fittings and controls directly associated with the boiler and, where consistent with the requirements of AS2593:2004 (Reconfirmed 2016), includes the boiler setting and associated equipment. It does not include fully flooded systems or pressurized systems where the water or other liquid is heated to a temperature lower than the normal atmospheric boiling temperature of the liquid" [1].

A typical boiler classification is shown in Figure 1. Boilers can be classified based on many parameters including boiler axis, passage, fabrication / manufacturing method, fuel source, working pressure and circulation method. The pressure vessel is usually made of steel (or alloy steel). The rapid uses of boilers began with the industrialisation and economic development. Hence, there is an increase of boiler hazards (serious injuries, deaths and destruction of properties). Today, boiler explosion is considered one of major threats to the industrial safety. It is significantly worst

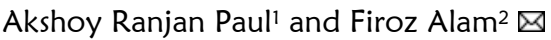

'Department of Applied Mechanics

Motilal Nehru National Institute of Technology Allahabad

Allahabad, India.

E-mail: arpaul2k@gmail.com

25chool of Aerospace, Mechanical and Manufacturing Engineering

RMIT University, Melbourne, Australia

E-mail: firoz.alam@rmit.edu.au

Reference: Paul, A. R. and Alam, F. (2018). Compliance of Boiler Standards and Industrial Safety in Indian Subcontinent. International Journal of Engineering Materials and Manufacture, 3(4), 182-189. 
in developing countries especially in the Indian subcontinent (India, Bangladesh and Pakistan). The primary objective of this paper is to highlight the alarming human deaths and injuries due to boiler explosions in the Indian subcontinent and some remedial actions that can be undertaken to minimise these losses. In vaporised condition, the volume of water is more than 1,000 times larger than that of liquid form. This highly pressurised water steam can rapture the metal shell and/or disintegrate the poorly welded or rusted joint leading to a violent eruption of the pressurized steam causing death, injury and destruction of property (sometimes entire building along with its occupants). For example, a boiler explosion in R. B. Groover shoe factory in Brockton near Boston at Massachusetts, USA killed 58 people and injured over 150 people in 1905. The explosion was so intense that boiler parts ripped through the floors and levelled the four-story wooden building turning it into a crematorium [3]. The Groover shoe factory before and after the boiler explosion is shown in Figure 2. The Groover disaster triggered the formulation of the US national boiler code/standard (by ASME) governing the safe design, construction, operation and maintenance of boilers [3,4]. Today most national and international standards are primarily based on ASME boiler standards.

\section{BOILER EXPLOSIONS IN INDIAN SUBCONTINENT}

Boiler accidents and loss of lives are not new in the Indian subcontinent. The British India's Boiler Regulation was the catapult of a tragic boiler explosion in Kolkata in 1863. The Bengal Council passed a bill in 1864 to inspect the steam boilers in and around Kolkata. Other Indian provinces later followed, and eventually the British established a uniform set of regulations in 1923 called 'Indian Boilers Act 1923', which covers inspections, penalties and conditions for material procurement.

Boiler/pressure vessel explosions data is difficult to obtain as most industries keep boiler accident/incident data in house and unreported. This practice is associated with the non-compliance of national boiler standards, corruptions, and legal litigations [2,11]. As there is no reliable boiler explosion data on Indian sub-continent is currently available in the public domain, the authors have used the boiler/pressure vessel incident reports' database of the US Occupational Safety and Health Administration (OSHA), National Board of Boiler and Pressure Vessel Inspectors (NBBPVI) and Wisconsin Boilers Inspectors Association (WBIA) [5,6,7,11]. Only incidents/accidents data applicable to the boiler/pressure vessel are used in this study. The OSHA and NBBPVI maintain US data while the WBIA keeps a record on global events that reported in print/electronic media. The authors have analysed the global boiler/pressure vessel accident/incident reported data from 2012 to 2017.

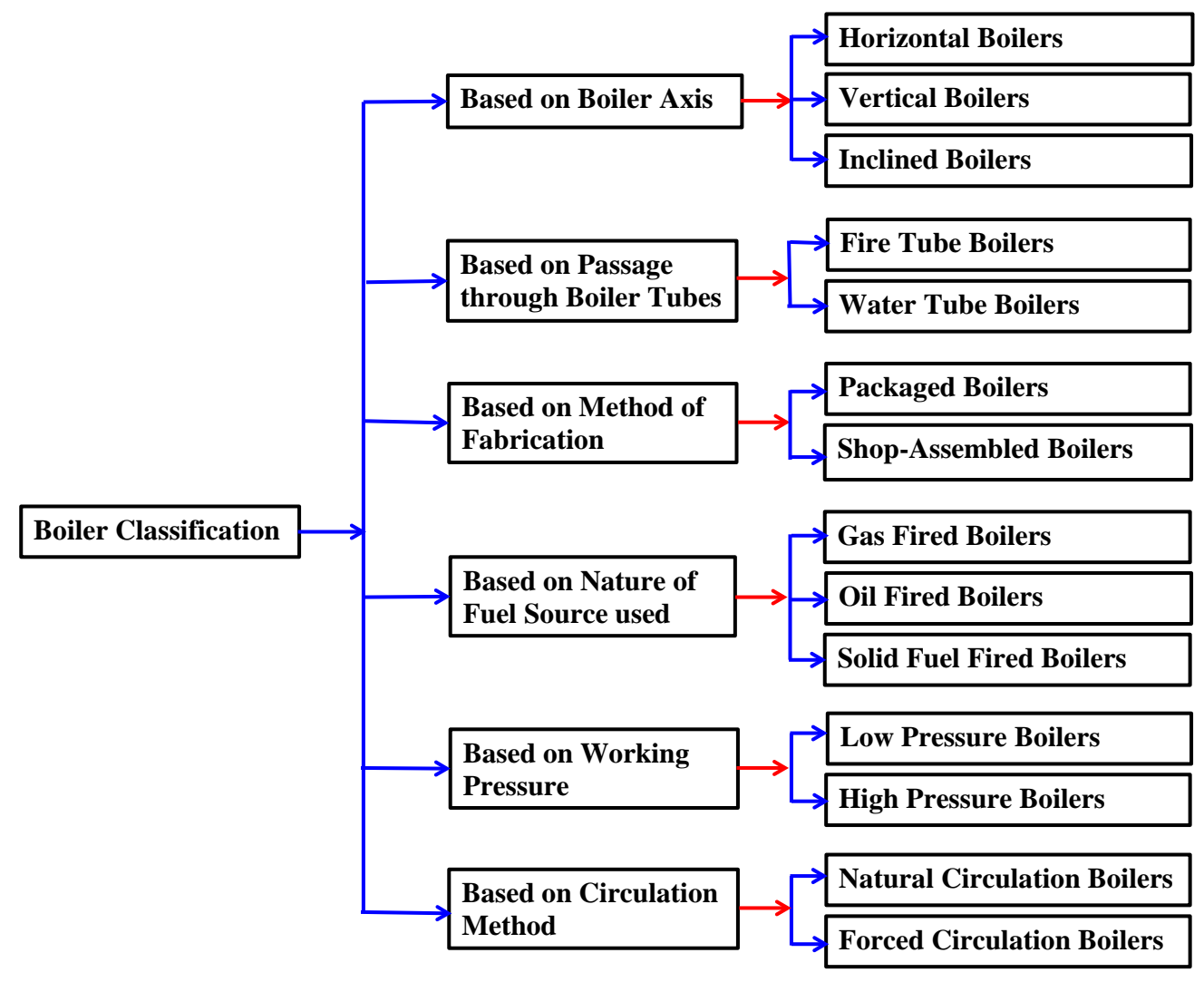

Figure 1: Boiler classifications, adapted from [2] 

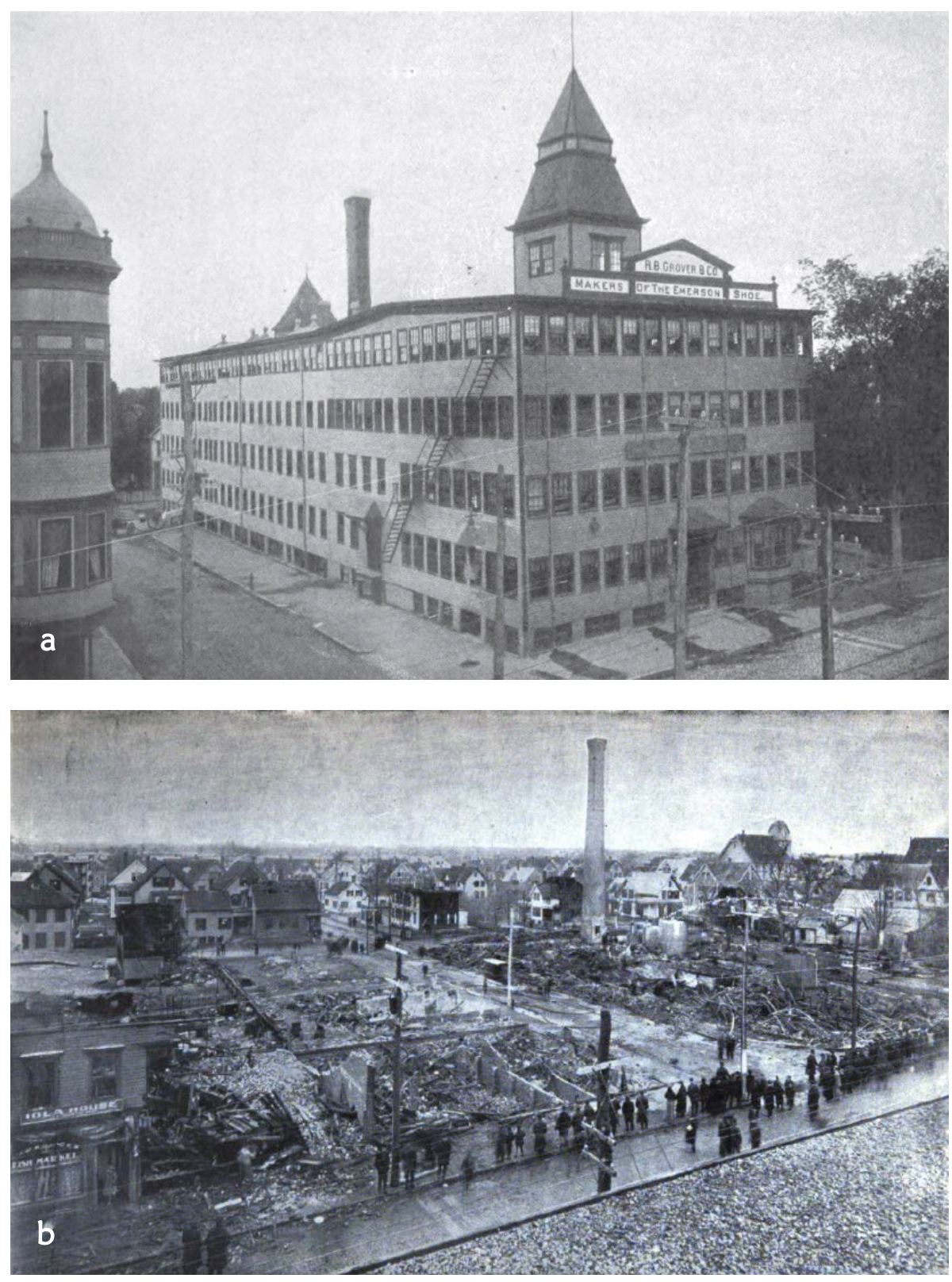

Figure 2: Boiler explosion at Groover shoe factory, adapted from [3,4,5]. (a) Groover Shoe Factory before the Boiler explosion on 20 March 1905, (b) Groover Shoe Factory after the Boiler explosion

A recent tragic boiler explosion at Multifabs garments factory at Kasimpur (near Gazipur) in Bangladesh killed 13 people and seriously injured over 50 people on 3 July 2017 [8]. The intensity of the explosion was so severe that it destroyed the concrete-built garment building as shown in Figure 3. Most victims are poor workers including the boiler operator. Two recent boiler explosions, one at a pharmaceutical unit of Probace Enterprises at Dombivli in Thane (India) on 26 May 2016 killed five and injured over 140 people (Figure 4). The blast has destroyed two buildings and partially destroyed three more buildings. The blast intensity shattered the window panes of all buildings within $1.5 \mathrm{~km}$ radius [9]. The other explosion was at National Thermal Power Company (NTPC)'s Unchahar 550 MW thermal power plant in Rae Bareli, Uttar Pradesh, India on 1 November 2017. The explosion killed 32 people and critically injured 97 people [10]. The boiler destruction images are shown in Figure 5 . The number of global death and injury due to boiler/pressure vessel explosions is shown in Figure 6. The numbers of deaths in the Indian subcontinent (Bangladesh, India and Pakistan) are progressively higher compared to the rest of the world since 2012. For example, the death numbers in developed countries (e.g. USA, Germany, UK, Belgium and Bulgaria) are only 20 compared to 248 deaths in Bangladesh, India and Pakistan over the same period. The boiler explosion death is 12.4 times higher in the Indian subcontinent than the rest of the world. A total of 726 people were severely injured in 
Bangladesh, India and Pakistan as compared to only 366 people globally. Again, the subcontinent boiler explosions caused nearly two times more severe injuries than the rest of the world. Figure 7 also shows an increased trend of death and injury in the subcontinent since 2012.

The number of catastrophic boiler explosions and fatalities are increasing progressively in India and Bangladesh since 2012, which is shown in Figure 7. It is alarming to note that over $76 \%$ global deaths due to boiler explosions occurred in the subcontinent. India topped the list with 34\% of the global death, closely followed by Bangladesh (21\%) and Pakistan (21\%). The boiler explosion death in India is higher than Bangladesh or Pakistan as India's registered boiler numbers are significantly larger compared to Bangladesh and Pakistan combined. India, Bangladesh and Pakistan are also responsible for over $66 \%$ global boiler explosion related human injuries compared to the rest of the world's 34\% (Figure 8). India again leads with 33\% followed by Bangladesh (19\%) and Pakistan (14\%).

In 1973 , there were over 20,000 industrial boilers including roughly 500 power boilers in India $[14,17,20]$. Most boilers used in textile industries, followed by rice mills, distilleries, engineering and chemical industries. The percentage of shell boilers was largest being about $78 \%$, water tube $14.5 \%$, and package $7.5 \%$ [14]. It is believed to be the boilers number in India in 2018 is over 100,000.

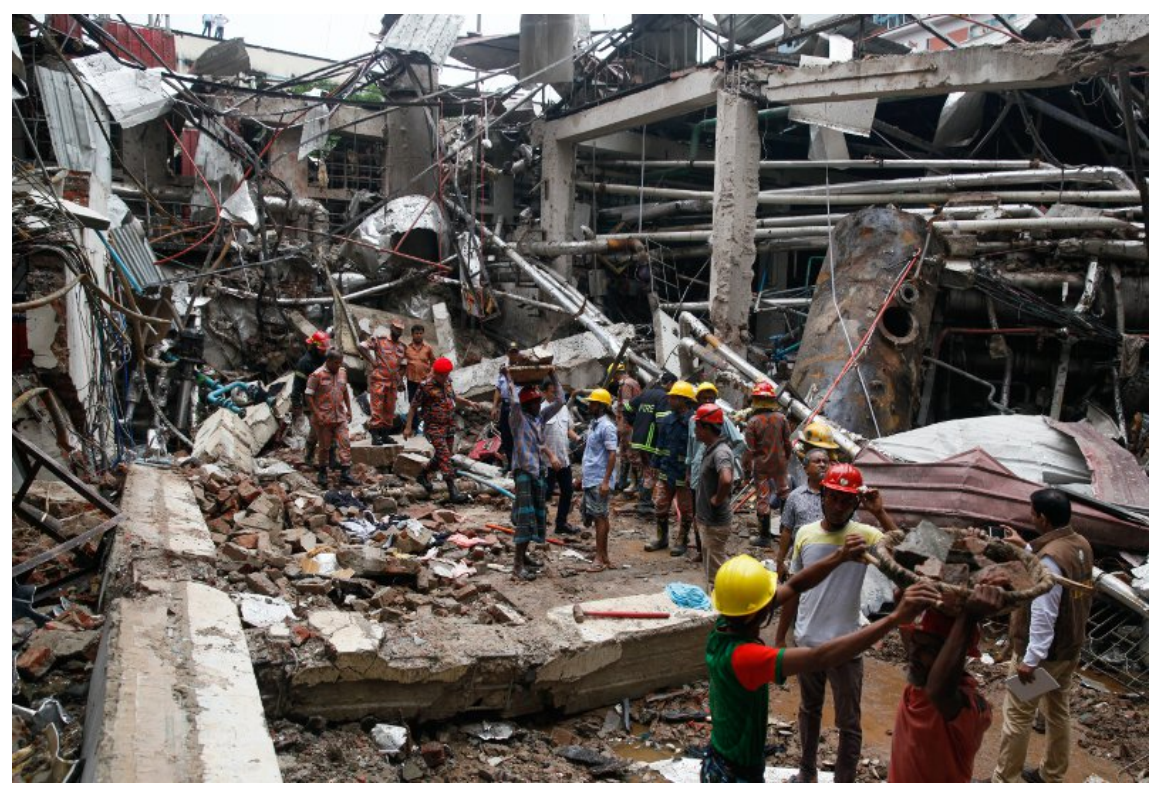

Figure 3: Boiler explosion at Multifabs garments factory, Kasimpur (near Gazipur), Bangladesh [8]

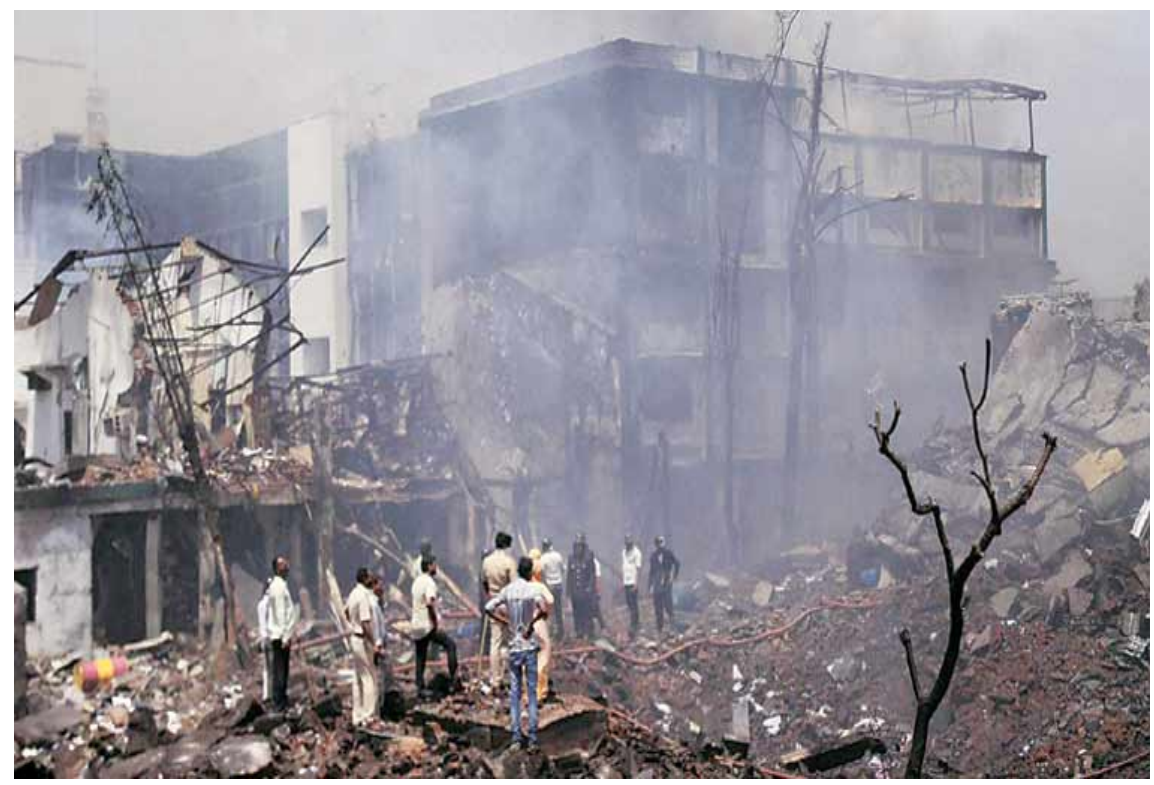

Figure 4: Boiler explosion at Probace Enterprises pharmaceutical unit at Dombivli, India [9] 

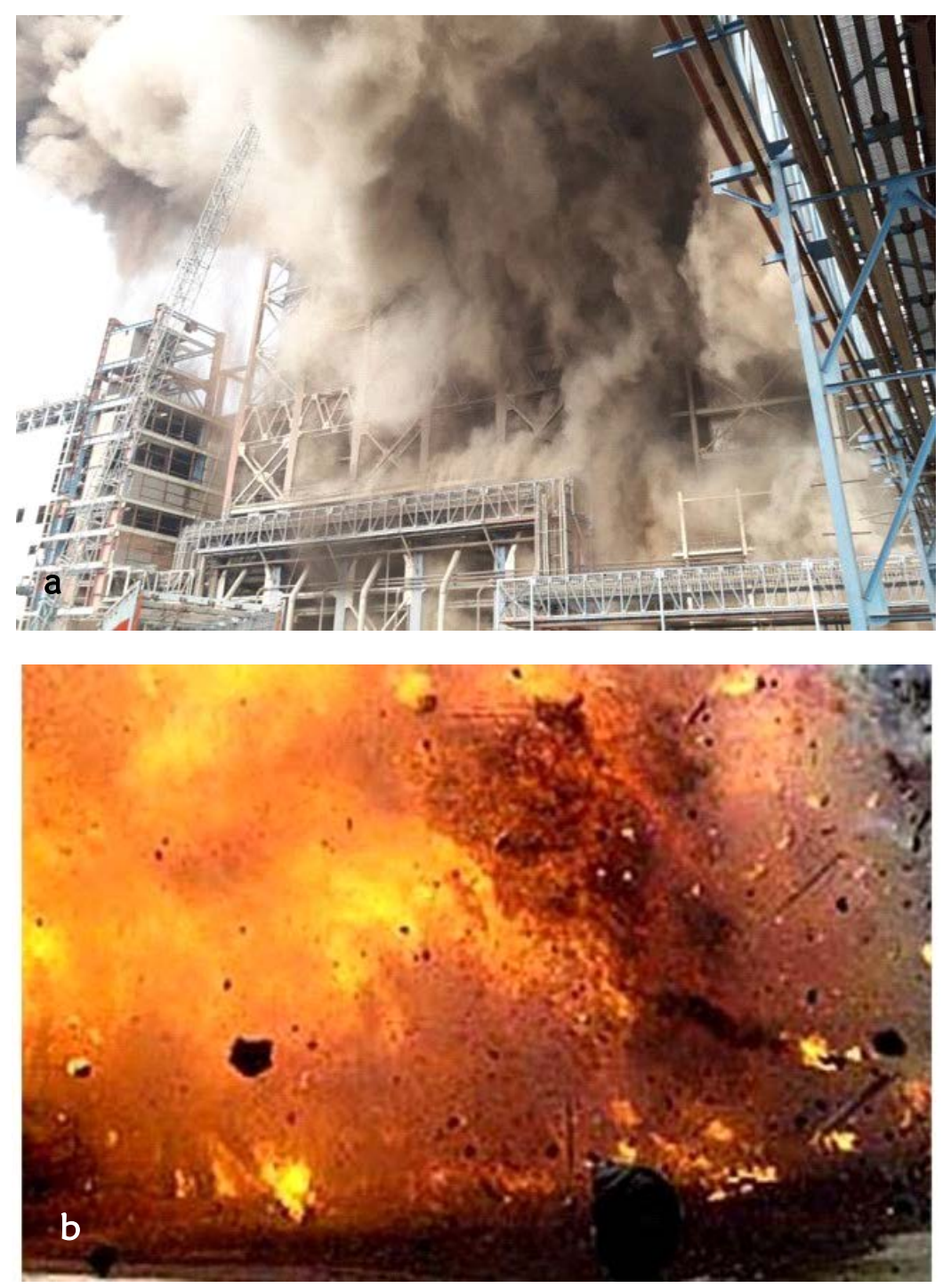

Figure 5: Boiler explosion at NTPC's Unchahar thermal power plant in Rae Bareli, Uttar Pradesh, India, adapted from $[12,13]$. (a) Boiler explosion at NTPC power plant, (b) Fiery destruction after boiler explosion

In Bangladesh, there are over 10,000 registered boilers. Additionally, there are over 2,000 boilers unregistered in Bangladesh [15]. The Boiler Inspection Department of Bangladesh has only 7 inspectors and a chief inspector to inspect over 6,500 registered operational boilers (out of 10,000) throughout the country [16]. Over 47 years ago in 1971, there were 700 registered boilers and four boiler inspectors and a chief boiler inspector. Now after 47 years, the number of inspectors increased to 7 from 4 but boiler number has increased to over 10,000 [15]. The number ratio of boilers and boiler inspection is 1250 (in 2018) and 140 (in 1971). This figure clearly indicates why Bangladesh has become one of the leading countries ( $2^{\text {nd }}$ in South Asia after India) for boiler explosion deaths and injuries. Currently, each of seven boiler inspectors is assigned to inspect on average of 100 boilers per month. However, in reality, they can hardly inspect one-third of assigned boilers. As a result, the defective and registration-expired boilers continue to operate. There is no strict compliance of boiler standards for the material, design, and construction in Bangladesh, despite locally manufactured boilers are increasingly filling gap of boiler needs along with imported in Bangladesh.

Pakistan Boiler Act is based on Indian Boiler Act 1923. Like India, each province has boiler board who undertakes boiler registration, inspection and certification. At present, no data is available in public domain about the registered boiler numbers in Pakistan. However, it is believed that the number should be at least 8,000 to 10,000. 


\section{DISCUSSIONS}

The demand for industrial and domestic boilers has been increasing in all countries of Asia led by China, India, Japan, South Korea, Indonesia, Bangladesh, Vietnam, Pakistan, Philippines, Thailand and Malaysia. A recent study undertaken by Global Market Insights has revealed that the global boiler market (industrial, utility, commercial and residential) is expected to be over US\$50 billion by $2024[17,18,19,20,21]$. In the subcontinent, India has the largest boiler market with annual growth of $24 \%$ followed by Bangladesh and Pakistan. Indian boiler market is mainly driven by energy and power industries [20]. The garment and textile sector are the main clientele for boilers in Bangladesh. About $70 \%$ of the boiler requirements of the garment and textile sectors are met through domestic manufacturing units. Poultry, feed mills, pharmaceuticals, food industries, auto rice mills, packaging, printing and leather industries are the major industries in Bangladesh that require boilers. Large boilers in Bangladesh are mostly imported. With the sustained growth in garments and textile industries in Bangladesh at an annual rate of 7\%, there are large demands for boilers, which are expected to increase at a rate higher than the global demand of 4\% [17].

After reviewing the Boiler Act 1923 and Boiler Regulations of India (1950), Boiler Regulations of Bangladesh (1951 amended in 2007) and Pakistan (1951), it is noted that all these countries have identical framework based on historical 'Indian Boiler Act 1923'. Office of the Chief Inspector of Boilers is the main regulatory body to look after the regulatory aspects of this sector in these countries. It also conducts registration of boilers, inspection and recommends for repairs, etc. The Boiler Board- as a high-powered technical body reviews/approves technical standards, designs, testing and inspection of boilers. Trained manpower and equipment strength of the office are inadequate to operate effectively while ensuring safe operation and maintenance of boilers. 'The Boiler Act 1923' is old and other regulatory frameworks are also outdated. The boiler rules/regulations and standards need continuous upgradation as new materials, technologies, control and monitoring systems are emerged. The boiler standards developed by ASME (USA), Standards Australia (AS), International Organization for Standardization (ISO) and other developed countries are being reviewed and updated regularly. The Boiler Act 1923 needs to be thoroughly revised and updated as per ASME (USA) and Standards Australia as these two standards are most up to date and incorporated all necessary aspects starting from design, manufacture, inspection \& certification, operation, maintenance and repair.

Some major issues with the boiler are proper operation, maintenance and repair. It is specially so in the Indian subcontinent. According to the US National Fire Protection Association (NFPA), the boiler explosions in the US are caused by the operator error (47\%), insufficient purge (39\%), control failure $(11 \%)$, and equipment failure $(3 \%)$ [22]. No such data is available for the Indian subcontinent. Therefore, the awareness about the boiler explosion should be part of core values in operating a boiler. In addition to the full compliance of national standards and boiler regulations, the boiler user should: a) have qualified personnel on site to manage the boiler, b) run scheduled preparedness drills, and c) undertake regular boiler checks and services.

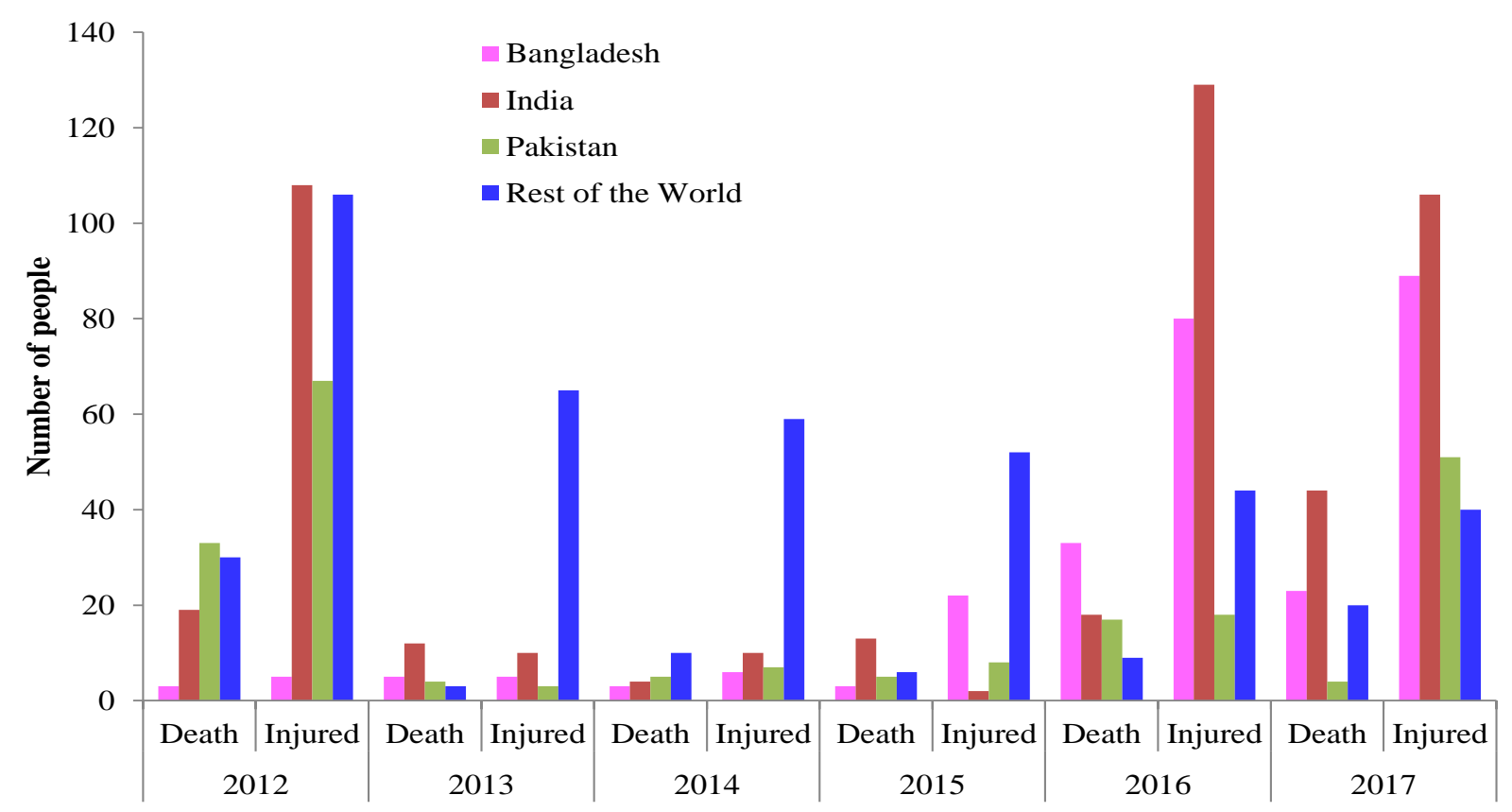

Figure 6: World-wide boiler explosion fatalities from 2012 to 2017, adapted from [5, 11] 


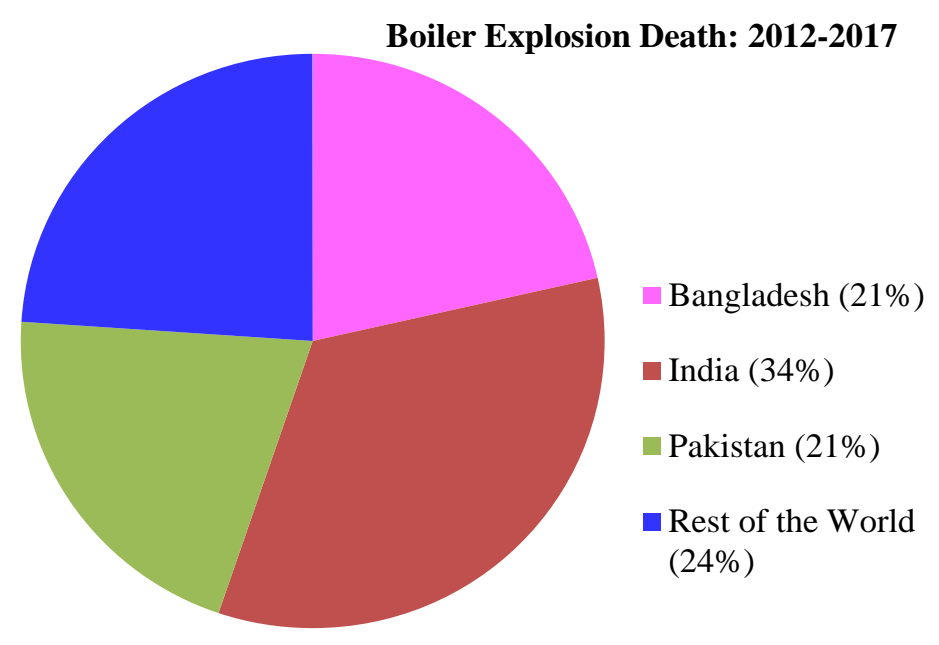

Figure 7: Deaths due to boiler explosions in Indian subcontinent from 2012 to 2017

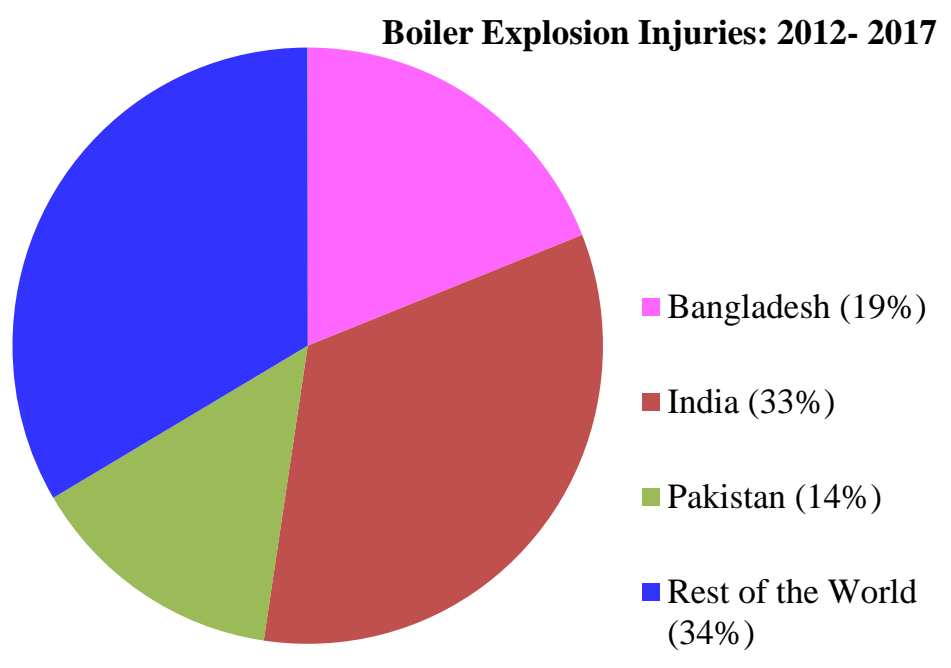

Figure 8: Injuries due to boiler explosions in Indian subcontinent from 2012 to 2017

There appears to be a knowledge gap among industrial managers about boiler regulations and safety in the Indian subcontinent. Boilers rules in these countries cover features such as inspections and certification, registration, accident investigation, penalties etc. The rules particularly cover the holding of examinations and awarding competency certificates to boiler attendants and boiler engineers and even welders. Those assigned to boilers need to be fully conversant with their operations to avoid exposing themselves and others to risk of accidents. However, these rules are often flaunted/ violated while implementing on the grass root levels. The public and private sectors using industrial, utility and commercial boilers must recognise that the function of these laws is not merely to regulate business and industrial activity, but to avoid accidents, injuries, illnesses and loss of property. 


\section{CONCLUSIONS}

Based on the present study, the following remedies are suggested to avert boiler related accidents and health hazards in the Indian subcontinent.

1. Revise the boiler codes/standards and regulations in view of ASME (USA) and Standards Australia (AS).

2. Create a pool of technical experts in boiler technology and operations to regulate the sector and maintain quality to avoid inherent risks.

3. Strictly maintain Boiler Operation Log Program and Maintenance Log Program (on daily, weekly, monthly, semi-annual and annual basis).

4. Arrange regular training programs on safety aspects for managers, engineers/operators, workers, welders working with the boilers.

5. Develop a national database for boiler registrations, renewal, explosions, causes of explosions and remedial actions.

6. Provide resources (skilled manpower, finance and equipment) to the National Boiler Board to carry out vested duties and responsibilities as per national standard and/or international standards.

\section{Acknowledgement}

The authors express their sincere gratitude and thanks to Professor Dr. M. A. Rashid Sarkar, Department of Mechanical Engineering, Bangladesh University of Engineering and Technology (BUET), Dhaka for sharing his knowledge on boiler operations in Bangladesh with us.

\section{REFERENCES}

1. Australian Standard AS2593: 2004 Reconfirmed 2016, Standards Australia, Sydney, Australia

2. Agarwal, S. and Suhane, A. (2017), Study of Boiler maintenance for Enhanced Reliability of Systems - A Review, Materials Today Proceedings, Vol. 4: 1541-1549.

3. Canavan, D.A. (2005). Remembering the 1905 Groover Shoe Factory Explosion, Bulletin, 60 (3), 9-12.

4. Varrasi, J. (2011). The try harnessing of steam, Mechanical Engineering magazine by ASME, March, USA

5. Wisconsin Boilers Inspectors Association, http://thewbia.com/, Accessed on 25 April 2018.

6. The National Board of Boiler and Pressure Vessel Inspectors, http://www.nationalboard.org, Accessed on 5 May 2018.

7. The US Occupational Safety and Health Administration, https://www.osha.gov/oshstats/, Accessed on 10 August 2018.

8. The Dhaka Tribune, Accessed on 25 July 2017. http://www.dhakatribune.com

9. The Indian Express, Accessed on 27 May 2016. http://www.indianexpress.com

10. The Hindu, 3 November 2017, http://www.thehindu.com/news/national/other-states/boiler-explodes-in-ntpcunchahar-plant/article19961812.ece, Accessed on 30 January 2018.

11. Paul, A. R. and Alam, F. (2018), Compliance of Boiler Standards and Industrial Safety in Indian Subcontinent, Proceedings of the Proceedings of the 1st International Conference on Mechanical Engineering (INCOM18), Paper no. 258, Jadavpur University, Kolkata, India, 4-6 January.

12. India Today magazine, accessed on 20 March 2018. https://www.indiatoday.in/india/story/uttar-pradesh-boilerblast-rae-bareli-ntpc-boiler-unit-1077764-2017-11-01

13. India Blooms News Service (IBNS), Kolkata, India, accessed on 11 March 2018. https://www.indiablooms.com/news-details/N/35441/boiler-blast-at-ntpc-power-plant-in-up-kills-8.html

14. Murgai, M.P. and Chandra, R. (1990), Boiler Operations (Progress in Energy Auditing and Conservation, ed. Sodha, M.S), New Age International, New Delhi, p. 341, ISBN: 81-224-0285-2.

15. Daily Kaler Kantha, Accessed on 6 July 2017. http://www.kalerkantha.com

16. The Office of the Chief Inspector of Boilers, Bangladesh, http://www.boiler.gov.bd/ Accessed on 1 August 2017.

17. Global Market Insights, Accessed on 17 July 2017. https://www.gminsights.com/industry-analysis/boiler-market

18. Bahadori, A. (2016). Essentials of Oil and Gas Utilities: Process Design, Equipment, and Operations, Oxford: Gulf Professional Publishing, UK.

19. Tredgold, T. (1827). Principle and Construction of the Steam Engine, Taylor \& Francis, London, UK.

20. Business Wire, Accessed on 15 July 2017http://www.businesswire.com/news/

21. Tyagi, S. (2014), Indian Power Boiler Market: Present \& Future, Energetica India, 4-6.

22. The US National Fire Protection Association, Accessed on 5 May 2017. http://www.nfpa.org 